\title{
Hospital Technical Efficiency Measurement Through of a Stochastic Frontier Cost Panel
}

\author{
Joao Serafim Tusi da Silveira ${ }^{1}$, Lucelia Ivonete Juliani ${ }^{1}$, Lucas Veiga Avila ${ }^{2}$, Jose Tavares De Borba $^{3}$ \\ ${ }^{1}$ PPGGEO, Universidade Regional Integrada do Alto Uruguai e das Missoes - URI, RS, Brazil \\ ${ }^{2}$ Phd Student, University of Santa Maria; Professor, University State of Rio Grande do Sul, UERGS, Brazil \\ ${ }^{3}$ Professor, Coordenador de Curso de Pos-Graduacao Lato Sensu no Centro Universitario, Católica de Santa \\ Catarina, Brazil
}

Correspondence: Joao Serafim Tusi da Silveira, PPGGEO, Universidade Regional Integrada do Alto Uruguai e das Missoes - URI, RS, Brazil. E-mail: joaotusi@hotmail.com

Received: August 23, 2016

Accepted: September 14, 2016

Online Published: October 24, 2016

doi:10.5539/ibr.v9n11p208

URL: http://dx.doi.org/10.5539/ibr.v9n11p208

\begin{abstract}
This article aims to evaluate the relative technical efficiency of the three clinics belonging to the University Hospital of the Federal University of Santa Catarina, RS, Brazil, in a two years period. The specification of the econometric model includes the analysis of productive sectors from the same institution in different periods of time. A stochastic frontier cost $\mathrm{CD}$ function using the composed error model was estimated by maximum likelihood (MLE) for a monthly data panel. The efficiency measures were computed using the formula adapted to the costs, based on parameters estimated by MLE. The results are encouraging and intriguing, especially regarding the inclusion of new variables, the expansion of the sample and the real utility of the efficiency ratios in the effective management task of productive resources within a single firm.
\end{abstract}

Keywords: hospital technical efficiency, stochastic frontier cost panel, econometric model

\section{Introduction}

The traditional econometric produces an average estimation of cost or production function, which is incompatible with the conception of a certain region of minimum cost for different levels of product or maximum product for different input levels. Farrell (1957) developed empirically the minimum cost idea, assuming a production function with constant returns of scale and decomposing the efficiency into: technical and allocative. In this way, the excessive use of input is interpreted as technically inefficient because it is possible to reduce all of them proportionally without reducing the product level while the allocative inefficiency is related with incorrect proportions in the use of factors. Thus, the ratio of the distance from the origin of the actual isocost line to the line least-cost tangency isocost line expresses a measurement on the degree of cost inefficiency. Implementation of this idea has being developed by mathematical programming (through Data Envelopment Analysis - DEA) and econometric method.

Since Farrell's paper (1957) has increased the interest of researchers for the utilization of frontier functions in efficiency econometric analysis in many different activity sectors as in private or public sectors. In the field of medical hospital care arise the U.S. authors contribution included in the "Symposium on Frontier Estimation" (Journal of Health Economics, 13(3): 255-382, 1994). Not only in these but, also in other developments it is common the fact that they direct exclusively in comparison between firms.

It is amazing that not too much attention was given to this subject in efficiency measures literature. With the purpose of investigating the cross-firm problem it is not known other applications but only the works of the same authors of this paper (one with DEA approach and the other with econometric approach, respectively, Pereira et al., 1995 and Silveira et al., 1995) and DEA assessment of physician efficiency in a hospital founded by Chilingerian (1995).

In comparison with deterministic production frontiers that are estimated in these three researches, in this present paper it was treated more deeply within the stochastic frontier, through the use of dual values of least cost. Primarily, it is discussed the econometric specification possibilities of analysis model: cost or production function? In one or more equations? Stochastic or deterministic frontier? And cross-section data, temporal series 
or panel data? After making the choice of the stochastic frontier cost and panel data, in section 3 is preceded by an empirical application in a case at the clinic of Federal University Hospital of Santa Catarina. Based on analysis of obtained results, and at the end of the section are emitted some conclusions and recommendations mainly to elaborate future researches.

\section{Model Specification}

The first aspect to be considered at the model specification is the choice of approach: production or costs approach.

When Wagstaff (1989) analysing Spanish hospital sector efficiency he used frontier cost models instead of production models to compare empirically the deterministic cost frontier, the cross-section stochastic cost frontier and a panel data stochastic cost frontier in which inefficiency is maintained constantly over time. In this study, no justification was presented why production frontiers was not used.

Zuckerman et al. (1994), without worrying about justifying their preference, used frontier cost functions in a comparative study about hospital efficiency in the United States. Vitaliano and Toren (1994a), compared the performance of nursing homes in New York and opted by cost frontiers estimation to measure jointly allocative and technical efficiency. Thus, they worked with the exogenous assumption of input prices in a cost function, which is much more likely than the exogenous in quantities in a production function can avoid simultaneity problems, since it was used a single equation model. Besides, it was claimed that the output price regulation of the sector in the study is consistent with cost function estimation.

The adopted specifications of these three researches are perfectly applied within Brazilian hospitals, especially at Universities. Besides the mentioned advantages of cost function it should be added the fact that econometric can still not be treated in a direct and simultaneous way of production functions with more than one product in one or more equations. Therefore, since then, it is chosen dual possibilities of least-cost frontiers instead of maximum income or profit, which are more applicable to activities centered in profit.

In turn, the adoption of a cost model of cross-section to a single equation implies in consideration that each clinic be a Decision Making Unit (DMU) that uses input vector $x \in \mathfrak{R}_{++}^{n}$, available at fixed prices $w \in \mathfrak{R}_{++}^{n}$, to produce an output vector $y \in \mathfrak{R}_{++}^{m}$ at a cost observed $C_{i}$, with technology:

$$
\begin{gathered}
C_{i}=f\left(y_{i j}, w_{i j} ; \beta\right) \exp \left\{v_{i}+u_{i}\right\} \\
C_{i}=f\left(y_{i j}, x_{i j} ; \beta\right) \exp \left\{v_{i}+u_{i}\right\}
\end{gathered}
$$

Where $i$ denotes $\mathrm{i}_{\mathrm{th}}$ clinic (DMU); $j$ denotes $\mathrm{j}_{\text {th }}$ output, input or price; $\beta$ is a vector of technology parameters (to be estimated); the term $v_{i}$ aims to embody the effects of statistical noise and random shocks and it is assumed to be independent and identically distributed as $N\left(0, \sigma_{v}^{2}\right)$; and the $u_{i}$ disturbance term is assumed to be independently of $v_{i}$ and satisfies $u_{i} \geq 0$.

Models of this type were used in the three-referenced studies at the beginning of this section in order to construct estimates of hospital costs efficiency indexes (and nursing homes).

Using a single equation you lose the relative statistical efficiency gained that would come from frontier dual system estimation. Unfortunately, this approach "is in its beginning stage" according to Lovell (1993) who shows the cost standard translog system and input share created by Christensen and Greene (1976).

Another question to be answered is concerned with the presence or not of statistical noise and random shocks in the efficiency measure, or better, to the frontier if it is deterministic or stochastic. In the first case, the deterministic cost frontiers for (1) and ( $\left.1^{\prime}\right)$ are, respectively,

$$
f\left(y_{i j}, w_{i j} ; \beta\right) \text { and } f\left(y_{i j}, x_{i j} ; \beta\right)
$$

This type of frontier is unsuitable because it is considered as inefficient the random shocks and the statistical noise, which means, that the error component is entirely classified with inefficiency or cost excess. And, there is no obvious reason why a hospital is less inclined to random shocks than any other organization, or why a hospital cost function is less likely to have statistical noise than any other type of regression model.

This unsuitable is resolved by the use of stochastic cost frontier which (1) and (1') are, in the same order,

$$
f\left(y_{i j}, w_{i j} ; \beta\right) \exp \left\{v_{i}\right\} \text { and } f\left(y_{i j}, x_{i j} ; \beta\right) \exp \left\{v_{i}\right\}
$$

In this type of frontier, the error term is composed of two parts: the first vi, is a two-sided component that catch random shocks and statistical noise; the second, ui, is a one-sided term that reflects the cost inefficiency, in conformity with (1) and (1').

The first to estimate this model type were Aigner et al. (1977), Battese and Corra (1977) and Meeusen and van den Broeck (1977), separately but almost at the same time, according to Lovell (1993). The first researchers 
group assumed that the vi is normally distributed and it is independent ui and it is considered the latter term according to different distributions: half-normal and exponential. Other distributions were considered by other authors, but half-normal assumption is the most used, including frontier cost function applications (Vitaliano and Toren, 1994a). And, establishing a certain arbitrary form ui where there is the greatest problem of this type of model, both estimation and separation of error component terms. In addition to this formulation it is involved no correlated inefficiency assumption with any variables of cost function, instead of just producing average efficiency estimation for all clinics. Jondrow et al. (1982) first proposed this decomposition problem.

When there is the condition to observe each DMU more than once and to take in consideration of the evolution of its costs, outputs, inputs and quality over a period of time, it can be obtained better estimations of relative efficiency for each unit than of cross-section model. This approach, firstly drown by Schmidt and Sickles (1984), can be adapted to frontier cost models (1) and (1'), respectively, as

$$
\begin{gathered}
C_{i t}=f\left(y_{i j t}, w_{i j t} ; \beta\right) \exp \left\{v_{i t}+u_{i}\right\} \\
C_{i t}=f\left(y_{i j t}, x_{i j t} ; \beta\right) \exp \left\{v_{i t}+u_{i}\right\}
\end{gathered}
$$

Where $\mathrm{t}=1, \ldots, \mathrm{T}$ indicates the th time period. In these models the statistical noise and random shocks vary between clinics and time, as efficiency varies only between clinics.

Through a data panel the cost efficiency can be treated in two ways. In the first, inefficiency is considered as a fixed effect, so that it is regarded as being entirely systematic. The specific effects of each clinic (ui, clinic-effects) - that can be merged with the interception of the function $u_{i}>0$ e one-sided and constants over time. In this circumstance there is no need to have assumptions about $i=$ distribution and, if the inputs are variables over time, about its independence in relation to ui. This is inapplicable to hospital clinics, since the cost function can include variables that are maintained constants for long periods of time, as for example medical and nurse staff and number of beds. Besides, these inconveniences of the type of model in ui estimation it shares the same model properties of deterministic frontier model.

In the second way, efficiency is treated as a random effect, which means that it can be partly determined by chance. No assumption is established in relation to clinic-effect functional forms, but it is assumed that these effects are non-correlated with input utilization level - when the estimation was made by generalized least squares (GLS); and when by maximum likelihood estimator (MLE) it is then necessary to make assumptions about this two aspects. The main advantage of this type of panel data, independently of estimation method is to allow the inclusion of variables that are held unchanged over the time of observation.

Other important attraction refers to the fact that $e^{u_{i}}$ estimation (in logarithmic form) provides more accurately the Farrell measure of efficiency, derived by Battese and Coelli for panel data (Greene, 1993b). This measure E[ $e^{u_{i}}$ | $\varepsilon$ i], adapted for cost panel data, with ui half-normal, is

$$
E\left[e^{u_{i}} \mid \varepsilon_{i 1}, \ldots, \varepsilon_{i T_{i}}\right]=T E_{i}=\frac{\Phi\left[\mu_{i} / \sigma_{i}-\sigma_{i}\right]}{\Phi\left[\mu_{i} / \sigma_{i}\right]} e^{\mu_{i}+0.5 \sigma_{i}^{2}}
$$

Where $T E_{i}=$ Farrell's indexes of cost efficiency; $\varepsilon_{i t}=C_{i t}-\beta\left(y_{i j t}, w_{i j t}\right)$ or $\varepsilon_{i t}=C_{i t}-\beta^{\prime}\left(y_{i j t}, x_{i j t}\right) ; \Phi$ is the cumulative distribution function of the standard normal distribution; $\mu_{i}=\left(1-\gamma_{i}\right)\left(-\bar{\varepsilon}_{i}\right) ; \gamma_{i}=1 /\left(1+\lambda^{2} T_{i}\right)$; $\lambda=\sigma_{u} / \sigma_{v} ; \mathrm{e} \sigma_{i}=\sqrt{\sigma_{u}^{2} \gamma_{i}}$.

Testing the existence of variation between the efficiency indexes of different clinics may be calculated by the Lagrange multiplier test (LM) in which the null hypothesis $\sigma_{u}^{2}=0$ is tested through the statistic

$$
L M=\frac{N T}{2(T-1)}\left[\frac{\sum_{i}\left(\sum_{t} e_{i t}\right)^{2}}{\sum_{i} \sum_{t}\left(e_{i t}^{2}\right)}-1\right]^{2}
$$

Where $e_{i t}$ are the residuals obtained by ordinary least squares (OLS) on the restricted model. $N$ is the number of firms (clinics); and $T$ is the time period of sample of each clinic (Greene, 1993a)

Thus, after estimating the stochastic frontier cost function coefficients directly by MLE and doing LM test, can be estimated the Farrell's cost efficiency indexes, which the maximum will not be $T E_{i}=1$, since MLE estimators of $u_{i}$ are not normalized.

Without forgetting the assumption that these indexes are fixed in time, it is possible to arrange the data in turn, that estimated indexes (in a period of three or four months, etc), may be considered in each adopted period as another DMU. Thus, it may be observed alterations occurred in the efficiency indexes of one period to other.

Yet, regarding econometric specification possibilities for efficiency cost analysis recently applied at hospital 
medical care area are important the comments of Skinner (1994) and Dor (1994) about Vitaliano and Toren's researches (1994a) and Zuckerman et al. (1994), considered by Newhouse (1994) the state of art of efficiency frontier econometric: point to fixed effects panel with preferable at stochastic frontier function. In replying, Vitaliano and Toren (1994b) accept these opinions and choose random effects panel data.

And, it is this panel data that will be estimated in application showed as follows--through stochastic frontier Cobb-Douglas cost function.

\section{Results and Discussion}

In order to make the application of the panel model presented in previous section, it has been tested by three medical clinics (two for men and one for women) in an activity at University Federal Hospital of Santa Catarina. These three hospital internment units have similar installations (rooms and beds) and other resources are used in a shared way as in the laboratories and radiology exams case, for instance. The available medical specialties in each clinic also are the same. Therefore, the technologies involved in each clinic may be considered equivalents.

Selected variables are almost the same used by Wagstaff (1989). To measure the cost (cost) a monthly cost of post-admission inpatient days per bed1 is used. At explanatory variables are included in a monthly number of available beds (bed) and the production variations are expressed by monthly number of post-admission inpatient days per bed (caseflow). The first variable is a proxy for the capital stock of the clinic, since the cost function is a short-run function and the cost data comprehends just the running costs and exclude capital expenditures. The second, represents the output quantities produced and may be interpreted as a serious or complex proxy diagnosis. When the case flow is below the average flow associated with longer lengths of stay it is likely due to the occurrence of more severe cases in those mentioned by months in relation to the others (Wagstaff, 1989).

Considering, firstly, as exerting important influence on unitary costs it was also included the monthly average length of stay (stay) and mortality monthly rate (death). The first should have direct influence on efficiency cost performance because as it increases it must be reduced the quantity of inpatient days and, consequently, to cause arise in the cost of post-admission inpatient day per bed. The second is a variable that may represent both the risk level and complexity of the disease of the inpatient about the success degree (quality) of the services. It is known by management information that low mortality rates are related to low risk and less complex cases and, consequently, increase of discharges. This results in high bed turnover, increase of inpatient days, reduction in unitary costs and, therefore, are the improvement of efficiency cost. The monthly bed-occupancy rate, although available has not been used directly because it is already inserted in the caseflow.

The data of all those variables refers to inpatients integrally served by Health Single System and they are available, monthly, in three basic sources: Cost Assessment System, Hospital Price Indexes and Hospital Information System.

Table 1. Stochastic frontier Cobb-Douglas cost function estimated with panel data by MLE for $u_{i}$ half-normal

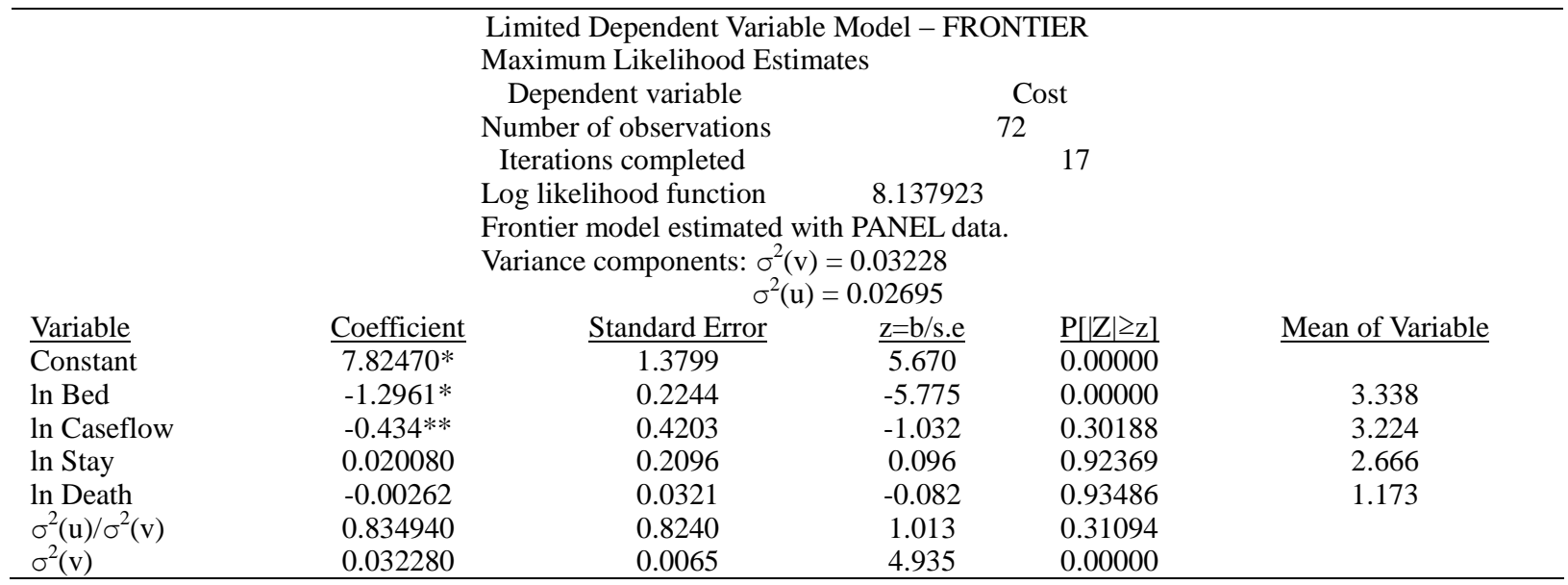

* Significant at $99 \%$.

** Significant at $85 \%$.

\footnotetext{
${ }^{1}$ All data cost were converted to constant prices using Hospital Price Index as a deflator. This index was calculated by the Financial Control Service of the Federal University Hospital of Santa Catarina, with the technique collaboration of Economics Department researchers.
} 
As soon as monthly data of these variables from year one and year two were organized the Frontier command of the software called LIMDEP - Limited Dependent Variable Models (Greene, 1995) has been used to estimate specific panel (2'). The main results may be seen in Table 1.

A balanced panel was chosen with periods of four months, because it was the best to correspond to the statistical demands of composed error model. The statistical value of Lagrange multiplier (Equation 4) is 4.3278, and should be compared with a tabular value of $\chi_{(1)}^{2}$ distribution to a significant level of 5\% (3.842). This test suggests, therefore, that there is significant variation in the efficiency between clinics at the $5 \%$ level, but not at $1 \%$. In spite of omitted variables and the smallest sample in terms of degree of freedom, the statistical performance of the model may be considered satisfactory.

It was observed in the above table that unitary costs are more susceptible to change the number of available beds than case flow. In turn, the coefficients of "stay" and "death" are far away to reach statistical significance, indicating that the unitary costs are maintained indifferent with changes that have happened in length of stays and deaths. Nevertheless, this must be evaluated with care. The raw data shows that both length of stay and death rates are too high, and vary too little around its averages of about 14 days and $7 \%$ in the same order (standard deviations of 0.21 and 0.028 , respectively). The profile of average length of stay is historically rooted in the work methods used to develop activities such as research, teaching and patient service. And death rate is not even far to represent both risk and complexity of disease and quality (success) of the performed treatments. To get to know more about these questions more specific studies should be made.

The efficiency calculation indexes in the period of four months for each clinic (by Equation 3) was carried out by LIMDEP through matrix operation commands. These indexes are in Table 2.

Table 2. Farrell's cost efficiency indexes based on MLE

\begin{tabular}{lccc}
\hline \multicolumn{1}{c}{ PERIOD/YEAR } & MMC I & MMC II & WMC \\
\hline year one & & & 0.6968 \\
January-April & 0.7860 & 0.6166 & 0.5983 \\
May-August & 0.7103 & 0.6428 & 0.8211 \\
September-December & 0.9257 & 1.0000 & 0.7972 \\
year two & & 0.8870 & 0.9928 \\
January-April & 0.8605 & 0.9259 & 0.7404 \\
May-August & 1.0170 & 0.7479 & \\
September-December & 0.5273 & & \\
\hline
\end{tabular}

It is verified by Table 2 that 1st Man Medical Clinic (MMC I) and 2th Man Medical Clinic (MMC II), or at least one of them as in the case of the first, penultimate and last periods of four months it is shown better cost efficiency indexes in comparison to Womanly Medical Clinic (WMC). These high relative persistent performances are due to, very likely, men trend in replying more quickly to oriented treatments. Therefore, the womanly clinic for to maintain equivalent levels of production as the others consume more input quantities per inpatient.

Among all clinics, the MMC I reached, in a period May-August 96, the best cost efficiency index (1.017) and, surprisingly, immediately in the next period of four months the worst index (0.5273). From one period to another the complementary exams expenses (laboratories, X-ray, supersonic, etc) and inpatient expenses that needed surgery increased considerably. This can be attributed to the fact that there is a substantial worsening, in the degree of severity and complexity, of the diseases treated in the period September-December of the year two.

Another important aspect is the fact that all indexes that referred to the first and second period (January-April and May-August) of the year two had been higher than the same periods of the previous year. These results come, mainly, from the in service of one more clinic (Maternity) that enables a greater global fixed costs share. The reasons why this did not repeat in the last period are the same already mentioned in the above paragraph, but just with less intensity in the womanly medical clinic case.

\section{Conclusions}

The stochastic frontier Cobb-Douglas cost function estimated by MLE for a monthly panel data concerning year one and year two, despite of not being statistically excellent, it is reproduced with good fit to the reality within medical clinics of Federal University Hospital of Santa Catarina, in the analyzed period, in relation to the variables presented. Also, the cost efficiency indexes calculated based on parameters of the referred function shows a strong explication power.

These results are already sufficient for some recommendations in a way to increase the relative level of efficiency costs. At middle-run, should be adopted both administrative and technical arrangements that change 
the working methods in relation to research and teaching with the purpose of decrease average length of stays. And, at short-run, should be installed more beds even to the point that there was no need of additional resources (except beds). This is possible because there is some idle capacity, and also because associated to the drop in the average length of stays there would be the increase of bed turnover and, consequently, of the discharges. All this would reflect in the reduction of the former level unitary costs and in the growth of the cost efficiency index.

For future studies there are recommended improvements. First, to increase the overall time period of the sample observation that should involve at least five years and to analyze various sub-periods, including the ones that do not correspond to an official sub-division. Second, to include remaining clinics since it has solved the output homogeneity problems. Third, to include variables that correspond to other inputs (laboratory exams, X-ray, etc...) as proxies of both risk and complex disease levels. And finally, to include variables that actually represent changes in the quality of the services.

\section{References}

Aigner, D. J., Lovell, C. A. K., \& Schmidt, P. (1977). Formulation and estimation of stochastic frontier production function models. Journal of Econometrics, $6, \quad$ 21-37. http://dx.doi.org/10.1016/0304-4076(77)90052-5

Battese, G. E., \& Corra, G. S. (1977). Estimation of a production frontier model: with application to the pastoral zone of eastern Australia. Australian Journal of Agric. Econ, 21(3), 167-179. http://dx.doi.org/10.1111/j.1467-8489.1977.tb00204.x

Chilingerian, J. A. (1995). Evaluating physician efficiency in hospitals: a multivariate analysis of best practices. European Journal Operational Res, 80, 548-574. http://dx.doi.org/10.1016/0377-2217(94)00137-2

Christensen, L. R., \& Greene, W. H. (1976). Economies of scale in U.S. electric power generation. Journal Polit. Econ, 84, 655-676. http://dx.doi.org/10.1086/260470

Dor, A. (1994). Non-minimum cost functions and the stochastic frontier: on applications to health care providers. Journal Health Econ, 13, 329-334. http://dx.doi.org/10.1016/0167-6296(94)90032-9

Farrell, M. J. (1957). The measurement of productive efficiency. Journal of the Royal Statistical Society, Series A, 120, 253-281. http://dx.doi.org/10.2307/2343100

Greene, W. H. (1993a). Econometric analysis (Macmillan, New York).

Greene, W. H. (1993b). The econometric approach to efficiency analysis, in: H.O. Fried, C.A. Knox Lovell e S.S. Schmidt, eds. The measurement of productive efficiency: techniques and applications (Oxford University Press).

Greene, W. H. (1995). Limdep. 7.0, (Econometric Software, Inc., Bellport, New York).

Jondrow, J., Lovell, C. A. K., Materov, I. S., \& Schmidt, P. (1982). On the estimation of technical inefficiency in the stochastic frontier production function model. Journal of Econometrics, 19(2/3), 233-238. http://dx.doi.org/10.1016/0304-4076(82)90004-5

Lovell, C. A. K. (1993). Production frontiers and productive efficiency, in: H.O. Fried, C.A. Know Lovell e S.S. Schmidt, eds. The measurement of productive efficiency: techniques and applications (Oxford University Press).

Meeusen, W., \& Broeck, J. V. D. (1977). Efficiency estimation from Cobb-Douglas production functions with composed error. International Econ. Review, 18(2), 435-444. http://dx.doi.org/10.2307/2525757

Newhouse, J. P. (1994). Frontier estimation: how useful a tool for health economics? Journal of Health Econ, 13, 317-322. http://dx.doi.org/10.1016/0167-6296(94)90030-2

Pereira, M. F., Lanzer, E. A., \& Silveira, J. S. T. (1995). Análise de eficiência produtiva de uma clínica cirúrgica utilizando análise de envelopamento de dados (DEA). Annals of Primeiro Congresso Internacional de Engenharia Industrial e XV ENEGEP, São Carlos (SP), Brasil.

Schmidt, P., \& Sickles, R. C. (1984). Production frontiers and panel data. Journal of Business and Econ. Statistics, 2(4), 367-374.

Silveira, J. S. T., Pereira, M. F., \& Lanzer, E. A. (1995). Análise econométrica de eficiência produtiva: aplicação à clínica cirúrgica do hospital da UFSC, III Workshop IPEA about Indicadores de Qualidade e Produtividade no Serviço Público, Brasília (DF), Brasil.

Skinner, J. (1994). What do stochastic frontier cost functions tell us about inefficiency? Journal of Health Econ, 
13, 323-328. http://dx.doi.org/10.1016/0167-6296(94)90031-0

Vitaliano, D. F., \& Toren, M. (1994a). Cost and efficiency in nursing homes: a stochastic frontier approach. Journal of Health Econ, 13, 281-300. http://dx.doi.org/10.1016/0167-6296(94)90028-0

Vitaliano, D. F., \& Toren, M. (1994b). Frontier analysis: A reply to Skinner, Dor and Newhouse. Journal of Health Econ, 13, 341-343. http://dx.doi.org/10.1016/0167-6296(94)90034-5

Wagstaff, A. (1989). Estimating efficiency in the hospital sector: a comparison of three statistical cost frontier models. Applied Econ, 21, 659-672. http://dx.doi.org/10.1080/758524897

Zuckerman, S., Hadley, J., \&Iezzoni, L. (1994). Measuring hospital efficiency with frontier cost functions. Journal of Health Econ, 13, 255-280. http://dx.doi.org/10.1016/0167-6296(94)90027-2

\section{Copyrights}

Copyright for this article is retained by the author(s), with first publication rights granted to the journal.

This is an open-access article distributed under the terms and conditions of the Creative Commons Attribution license (http://creativecommons.org/licenses/by/4.0/). 